\title{
CÉLULAS TRONCO MESENQUIMALES: DEFINICIONES, CULTIVO Y APLICACIONES POTENCIALES
}

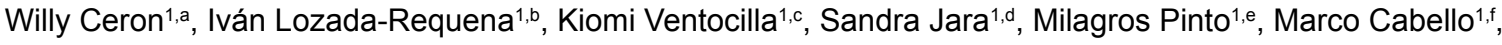 \\ José L. Aguilar ${ }^{1, g}$
}

\section{RESUMEN}

En los últimos años, las células troncales mesenquimales (Mesenchymal Stem Cells, MSC) han adquirido mucha importancia debido a su gran plasticidad y su capacidad de liberar factores paracrinos con capacidad de interactuar con diversos tipos celulares, tejidos y órganos. El uso de MSC en medicina regenerativa es importante debido a que, al no expresar las moléculas del complejo mayor de histocompatibilidad (MHC) clase II ni moléculas co-estimuladoras y tener baja expresión del MHC clase I, haría que no sean rechazadas por individuos de la misma especie, es posible utilizarlas no sólo de manera autóloga, sino también, eventualmente, alogénica. Sin embargo, es importante demostrar científicamente muchas de sus propiedades, entre ellas las inmunomoduladoras. Al tener varias fuentes de obtención, se debe estandarizar la que sea la mejor para garantizar la pureza y calidad de las MSC. Finalmente, es importante que cuando se trabaje con estas células se demuestre completamente las características del cultivo celular, la inmunotipificación y su capacidad de diferenciación. Se están ensayando muchas aplicaciones clínicas de las MSC. Dentro de ellas, su capacidad para mejorar la recuperación y potencial curación de úlceras crónicas como las diabéticas, ha atraído la atención por su potencial impacto terapéutico.

Palabras clave: Células madre mesenquimales, factores solubles, cicatrización, regeneración, úlceras crónicas (fuente: DeCS BIREME).

\section{MESENCHYMAL STEM CELLS: DEFINITIONS, CULTURE AND POTENTIAL APPLICATIONS}

\begin{abstract}
In recent years, mesenchymal stem cells (MSC) have become very important due to their high plasticity and their ability to release paracrine factors able to interact with various cell types, tissues and organs. The use of MSC in regenerative medicine became of vital importance, since they do not express histocompatibility MHC molecules class II nor costimulant molecules, and low expression of MHC class I, will not be rejected by individuals of same species, they could be used in an autologous, and eventually, allogeneic manner. However, it is important to scientifically demonstrate many properties, including immunomodulatory ones. Having several sources of obtaining, it should be standardized the best one to ensure the purity and quality of these cells. Finally, it is important when working with these cells, that characteristics of cell culture, immunophenotyping and differentiation capacity are fully demonstrated. MSC have been applied in several clinical uses. Among them, their ability to improve, and even heal chronic ulcers, as diabetic, has attracted attention for its potential therapeutic impact.
\end{abstract}

Keywords: Mesenchymal stem cells, soluble factors, wound healing, regeneration, chronic ulcers. (Source: DeCS BIREME).

\footnotetext{
1 Laboratorio de Inmunología, Laboratorios de Investigación y Desarrollo, Departamento de Ciencias Celulares y Moleculares, Facultad de Ciencias y Filosofía, Universidad Peruana Cayetano Heredia. Lima, Perú.

a Licenciado en Tecnología Médica; ${ }^{\mathrm{b}}$ magíster en Ciencias; ${ }^{\mathrm{b}}$ bachiller en Tecnología Médica; ${ }^{\mathrm{d}}$ estudiante de Biología; ${ }^{\mathrm{e}}$ bachiller en Ingeniería Biotecnológica; ${ }^{\mathrm{f}}$ licenciado en Biología; ${ }^{\mathrm{g}}$ médico especialista en Inmunología y Reumatología.

Recibido: 08/08/2015 Aprobado: 24/08/2016
}

Citar como: Ceron W, Lozada-Requena I, Ventocilla K, Jara S, Pinto M, Cabello M, Aguilar JL. Células tronco mesenquimales: definiciones, cultivo y aplicaciones potenciales. Rev Peru Med Exp Salud Publica. 2016;33(4):758-71. doi: 10.17843/rpmesp.2016.334.2563 


\section{INTRODUCCIÓN}

Se define como células madre o células tronco (Stem Cells, SC) a aquellas células cuya principal característica es la capacidad de autorrenovarse indefinidamente por división celular y que, bajo ciertas condiciones del microambiente celular y tisular, pueden diferenciarse a otros tipos de células especializadas, no sólo morfológica, sino también funcionalmente. Es así como una población pequeña de SC puede en unos meses proliferar hasta dar origen a millones de ejemplares con las mismas características de sus predecesoras ${ }^{(1,2)}$. Una de las características atribuidas a las SC, que potencialmente sirve como estrategia terapéutica, es que pueden reparar o reemplazar tejidos dañados, o revertir una enfermedad o lesión. Aunque, en los últimos años, su capacidad para inducir procesos paracrinos reparadores e inmunomodulación están cobrando mayor trascendencia en su aplicación clínica.

Una de las potencialidades que presenta una SC es su capacidad para diferenciarse en otros tipos celulares, lo que permite clasificarlas en totipotenciales, pluripotenciales, multipotenciales, oligopotenciales y unipotenciales ${ }^{(1,2)}$. Así mismo, de acuerdo a esta capacidad de diferenciación, diversos científicos se han dado a la tarea de buscar genes de pluripotencialidad, es decir, la capacidad de diferenciarse en la mayor parte de las células que componen el cuerpo humano, obteniendo como resultado que en el 2006 el investigador japonés Shinya Yamanaka (ganador del Premio Nobel en Fisiología o Medicina 2012) insertara genes de pluripotencialidad a una célula somática adulta y lograra hacer lo que se conoce hoy en día como SC pluripotentes inducidas (induced Pluripotent Stem Cells, iPSC). Este hecho ha sido un paso importante para incrementar el desarrollo de trabajos de investigación, que conlleven a la terapia celular.

Está demostrado que las SC tienen la capacidad de generar grupos celulares diferentes de los de su tejido de origen; tal es el caso de las SC hematopoyéticas (hematopoietic stem cells, HSC) y SC mesenquimales (mesenchymal stem cells, mesenchymal stromal cells, MSC), las cuales, bajo condiciones experimentales e incluso in vivo, pueden diferenciarse hacia diversos linajes celulares. Por ejemplo, las HSC pueden originar células musculares, nerviosas o hepáticas; mientras que las MSC se pueden diferenciar en condrocitos, osteoblastos y adipocitos. A todo este conjunto de características se le denomina plasticidad o transdiferenciación, encargadas de convertir a las SC en un recurso extraordinariamente prometedor, tanto para la investigación básica como para las aplicaciones clínicas ${ }^{(3)}$.

Además de las diferentes clasificaciones que son dadas a las SC, también generan gran interés los diferentes modelos de diferenciación celular a los que pueden ser conducidas, desde el modelo convencional célula madre - célula hija, hasta procesos de transdiferenciación, desdiferenciación y rediferenciación celular; es así como estos modelos son aplicados en la actualidad para entender el fenómeno de la "plasticidad" que ha sido reconocido en este tipo de células ${ }^{(3)}$.

El intenso estudio de las SC en los últimos años ha llevado al descubrimiento de nuevos ámbitos terapéuticos y experimentales.

En un inicio, Alexis Carrel, Premio Nobel en Fisiología o Medicina en 1912, realizó experimentos con trasplante y reparación de órganos logrando avances en la cirugía y cultivos celulares ${ }^{(4)}$.

En 1981, Martin Evans y Matthew Kaufman fueron los primeros en aislar exitosamente SC embrionarias (embryonic stem cells, ESC) de ratón y cultivarlas. Previamente, Ernst Haeckel y su equipo fusionaron los conceptos de filogenia y ontogenia para describir a las SC, como concepto para definir a las células primordiales que se diferencian en diversos tipos de células y en organismos multicelulares ${ }^{(5)}$.

En 1998, James Thomson desarrolló la primera línea de ESC humanas (human embryonic stem cells, HESC), derivadas exitosamente de la masa celular interna de un blastocisto producido por fertilización in vitro. Esta línea celular fue usada en el desarrollo de experimentos biológicos humanos, descubrimientos farmacológicos y en la medicina del trasplante ${ }^{(6)}$. Dichas células son una prometedora herramienta para la regeneración tisular, gracias a su gran capacidad de proliferación y su capacidad plástica de diferenciación, característica que las hace hábiles para regenerar la estructura del tejido herido. Cuando se encuentran bajo condiciones asépticas adecuadas, pueden diferenciarse en otros tipos de células especializadas con las mismas características de sus predecesoras ${ }^{(7-9)}$.

Específicamente, las MSC son una población de células progenitoras del linaje mesodérmico, que pueden producir distintas células especializadas como osteoblastos, condrocitos, adipocitos y fibroblastos (10). Fueron primero identificadas en la médula ósea, pero luego se expandió su descubrimiento en todo el cuerpo. Este tipo de células se encuentran en los llamados microambientes o nichos de SC, su rol principal es mantener la homeostasis y la reparación de tejidos a lo largo de la vida de un organismo (11). Además, las MSC secretan un amplio rango de mediadores solubles que les da interacción con diversos tipos de células (12). Investigaciones sugieren que estas MSC podrían diferenciarse en otros tipos de células fuera del 
tejido esquelético, como células cardíacas, del sistema nervioso o del hígado (13). Aunque ya se habla de potenciales terapias a base de MSC para el tratamiento de osteoartritis ${ }^{(14)}$ o enfermedades cardíacas ${ }^{(15)}$, queda mucho por descubrir sobre cómo trabajan estas células y cómo interactúan en nuestro cuerpo.

El estudio cada vez más profundo de estos tipos de células puede llevar a nuevas terapias y avances científicos, en beneficio del tratamiento de distintas enfermedades, sin pasar por alto todos los condicionamientos éticos.

\section{PROPIEDADES \\ INMUNOMODULADORAS DE LAS CELULAS TRONCO MESENQUIMALES (MSC)}

Numerosos estudios han descrito las propiedades inmunomoduladoras de las MSC. Se considera aquí la modificación de la proliferación y funciones de las poblaciones celulares del sistema inmune innato y adaptativo (16). Estas propiedades contribuyen al mantenimiento de la homeostasis inmune. Las investigaciones realizadas demuestran que las MSC, en condiciones determinadas, no siempre ejercen función inmunosupresora, sino que incrementan la respuesta inmune, esto se demuestra en condiciones de baja inflamación o cuando e nivel de citoquinas inflamatorias son insuficientes para la estimulación de MSC. Algunos autores proponen que las MSC podrían tener dos fenotipos: proinflamatorio o antiinflamatorio, y cada población podría tener características únicas y diferir en su secreción de citoquinas, capacidad de diferenciación, los depósitos de la matriz extracelular, las vías de señalización, y secreción de algunas moléculas como TGFß1, PGE2 o IDO ${ }^{(17,18)}$.

\section{EFECTOS INMUNOMODULADORES DE LA MSC SOBRE LAS CÉLULAS DEL SISTEMA INMUNE}

Linfocitos T (LT): una vez activados los LT inician su proceso de proliferación y diferenciación, el cual estará modulado por una gran variedad de mecanismos y moléculas presentes durante el primming (inicio de activación de un LT naive) y todo el proceso de activación de los linfocitos T. Se ha demostrado que las MSC ejercen un rol modulador de la población de linfocitos $T^{(18,19)}$.

Aunque actualmente existen resultados contradictorios sobre el efecto de MSC en la regulación de LT y sobre la secreción de citoquinas por los LT activados, se ha demostrado que estos resultados (regulación-activación) dependen del tipo de población, microambiente circundante y del estadio de activación en el que se evalúa esta población, llegándose a extrapolar a las MSC (como en la polarización del macrófago en M1 vs M2) en fenotipo MSC1 (proinflamatorio) y fenotipo MSC2 (antiinflamatorio) ${ }^{(20)}$ y esta polarización, en gran medida, depende de las moléculas que interactúen con sus respectivos ligandos, como la polarización que puede generar la interacción de un TLR con su respectivo PAMP (21). Se ha mencionado el potencial desarrollo de neoplasias por el uso de SC. En el caso de las MSC se ha descartado esta posibilidad ${ }^{(19)}$. Por otro lado, el uso de ESC ocasiona muchos conflictos éticos, sin embargo, con MSC se evita estos conflictos éticos por el hecho de obtenerse a partir de sujetos adultos ${ }^{(19)}$.

Después de la activación, las células Th0 se pueden diferenciar en Th1, Th2, Th17 o LT reguladores, entre las principales derivaciones. Generalmente, las MSC modulan esta diferenciación para generar una respuesta antiinflamatoria y de reparación tisular. Es así que se bloquea la inducción Th1, a través de la inhibición de la secreción de IFNr y en las poblaciones Th2 se incrementa la secreción de IL-4. Además, las MSC inhiben la producción de citoquinas proinflamatorias como IL-17, IL-22, IFNr, TNFa y la diferenciación de los LT a Th17, inducen la secreción de IL- 10, la activación del factor de transcripción Foxp3 y la diferenciación hacia $\mathrm{LT}$ reguladores, así como la producción de moléculas reparadoras y factores de crecimiento y reparación tisular ${ }^{(22)}$.

De tal manera que, la activación de MSC depende de la preexistencia de un entorno inflamatorio, la inmunomodulación que ejercen las MSC va a depender de la población celular sobre la cual actúe, modo de activación celular y si hay o no contacto celular ${ }^{(18,22)}$.

Linfocitos B (LB): las interacciones entre MSC y LB son un tema no bien desarrollado. A pesar que los LB nacen, maduran y actúan ya maduras importantemente en médula ósea, donde existe gran población de SC, el efecto entre ellas no es bien conocido. La actividad inmunomoduladora de las MSC sobre estas células, aparentemente, depende de factores solubles y de contacto celular mediado por la señal negativa que induce la molécula PD-1 y sus ligandos, reduciendo así su proliferación. También puede modificar la expresión de receptores para quimioquinas como CXCR4, CXCR5, y CCR7. La interacción MSC y LB es bastante compleja, depende de los diferentes tipos de LB e importantemente de factores paracrinos en el microambiente ${ }^{(23)}$. El efecto inhibidor de MSC sobre LB depende, además, de la inhibición de MSC sobre otras líneas celulares como LT, células dendríticas y macrófagos, y sus metabolitos secretados ${ }^{(23)}$. 
Células dendríticas y macrófagos: son fundamentales en la presentación de antígeno a los LT vírgenes (naive). Ambas células presentadoras de antígenos (CPA) pueden activar los LT o también inducir tolerancia dependiendo de su maduración, subtipo, las moléculas que expresen en superficie y su propio mecanismo metabólico. Las MSC ejercen un fuerte efecto inhibidor de células dendríticas (CD) sobre su diferenciación, maduración, expresión de moléculas de superficie de interacción con LT como las moléculas MHC II o moléculas de coestimulación como CD80, y en la inhibición o consumo de metabolitos utilizados por las CD (como PGE2, IDO, IL-6), afectando sus capacidades de activación del LT, secreción de citoquinas, disminuyendo la producción de radicales libres de oxígeno, metaloproteasas, citoquinas como IL$12, \mathrm{IFN} \gamma$, entre otras moléculas secretadas ${ }^{(24,25)}$.

Importantemente, las MSC inducen una polarización en macrófagos de tipo $M 2$, incluyendo la polarización a macrófagos M2 a partir de $\mathrm{CD}$ derivadas de monocitos ${ }^{(26)}$ y este paso podría estar mediado en parte por algunos metabolitos como el lactato, producidos por MSC, lo cual se convierte en un blanco terapéutico potencial ${ }^{(26)}$.

Células NK (NKc): su función efectora está regulada por sus receptores de superficie y por la secreción de citoquinas, tales como IFNr, IL-12, TNFß, y GM-CSF, y poseen actividad citotóxica tanto espontánea y dependiente de anticuerpos. Su acción es potenciada por otras células como los macrófagos, las células dendríticas y LT.

Por una parte, las NKc cumplen una función de reclutamiento de MSC, a través de la secreción de moléculas como la quimioquina RANTES (CCL5) o NAP2 (proteína activadora de neutrófilos tipo 2) (llamada CXCL7) que interactúa con su ligando el receptor para quimioquina CXCR2 en la MSC ${ }^{(27)}$.

Cuando se activan las NK en presencia de MSC, la interacción puede inhibir la producción de IFN- $\gamma$, la proliferación mediada por IL-2 e IL-15, además de la actividad citotóxica de las NK, disminuyendo la expresión de receptores de activación.

Las MSC producen mediadores, entre otros: PGE2, TGF- $\beta$ y HLA-G5 (fracción soluble del HLA estimulada por IL-10) que regulan (suprime) la función de las células NK en cultivo, lo cual regula también los procesos inflamatorios y propicia los procesos reparativos tisulares ${ }^{(25,28)}$.

\section{FACTORES SOLUBLES DE LAS MSC IMPLICADOS EN LAS PROPIEDADES INMUNOMODULADORAS}

TGFß1 y factor de crecimiento de hepatocitos (HGF): son expresados por las MSC y se cree que actúan en conjunto. EI TGFß1 está implicado en la generación de CD4+CD25+Foxp3+ Treg y reduce la proliferación de los linfocitos y NKc. EI HGF secretado por MSC cumple roles inmunorreguladores al favorecer la polarización M2 a través de MAP kinasas ${ }^{(29)}$. Estos factores de crecimiento son cruciales en los mecanismos inmunorreguladores de cualquier origen.

Indolamina-2,3-dioxigenasa (IDO): es una enzima que cataliza la conversión del aminoácido triptófano a quinurenina que regula la proliferación de LT. Las MSC no producen IDO espontáneamente, pero sí cuando son estimuladas por INFr o por ligandos de TLR-3 y TLR4. La producción de IDO no es el único mecanismo de inhibición de LT por MSC, pero es indispensable para la inhibición de LT inducida por IFNr (30). La inhibición de LT forma parte de los mecanismos inhibidores de inflamación para dar pase a los mecanismos reparadores tisulares.

Prostaglandina E2: las MSC producen PGE2, que es un metabolito lipídico, y está demostrado que disminuye la proliferación de LT, estimula la secreción de IL-4 e IL-10, y más bien promueve los LT CD4+CD25+ Foxp3+, o sea, la diferenciación a LT reguladores. En interacción con MSC también reduce la diferenciación de monocitos a CD, la proliferación y la citotoxicidad de las NK activadas por IL12 (30). Además, la PGE2 producida por MSC mantiene la autorrenovación de las MSC. Pero, así mismo, el contacto célula a célula de MSC inhibe la producción de PGE2, inhibiendo su capacidad inmunorreguladora, equilibrando, por lo tanto, el sistema, en un mecanismo similar a un feed-back ${ }^{(31)}$.

HLA-G5: esta molécula soluble es inducida por IL-10 y, a su vez, promueve la secreción de IL-10. Para ello es necesario contacto célula-célula entre MSC y LT. La interacción entre ambas resulta en un ambiente inmunosupresor potenciado por la generación de Treg ${ }^{(28)}$.

Galectinas: son proteínas que intervienen en la inmunomodulación de diversas formas, las MSC expresan galectina-3, molécula que regula la proliferación y adhesión de los LT. Así mismo, se ha demostrado la participación de la galectina-1 y galectina-9, donde la elevada expresión de estos ligandos en las MSC en un medio de inflamación reduce la proliferación de $\mathrm{LT}^{(32,33)}$.

\section{ROL DE MSC EN LA REGENERACIÓN TISULAR CUTÁNEA}

Dentro de las propiedades de las MSC que principalmente contribuyen con la regeneración tisular se encuentran: la autorrenovación, capacidad multipotente de diferenciación y la regulación inmune de la respuesta inflamatoria. El daño del tejido está siempre asociado 
con la activación de células inflamatorias/inmunes, es decir, macrófagos, neutrófilos y además LT CD4, LT CD8 y LB, los cuales son reclutados debido a factores generados desde las células apoptóticas, células necróticas, microvasculatura dañada y el estroma ${ }^{(34)}$.

Cuando las MSC ingresan al microambiente del daño tisular, factores locales como citoquinas inflamatorias (TNF- $\alpha, I L-1 \beta, I F N-\gamma$ ), radicales libres, quimioquinas, leucotrienos, toxinas de agentes infecciosos e hipoxia, pueden estimular a que las MSC liberen muchos factores de crecimiento que incluyen: factor de crecimiento epidermal (EGF), factor de crecimiento fibroblástico (FGF), factor de crecimiento derivado de plaquetas (PDGF), factor de crecimiento transformante-beta (TGF-beta), factor de crecimiento endotelial vascular (VEGF), HGF, factor de crecimiento insulínico tipo 1 (IGF-1), angiopoyetina-1 (Ang-1), factor de crecimiento de keratinocitos (KGF), y factor derivado de células estromales tipo 1 (SDF-1). Las interacciones entre estos factores promueven el desarrollo de fibroblastos, células endoteliales, células progenitoras tisulares que regeneran y tienden a reparar el tejido dañado ${ }^{(35)}$.

La presencia de MSC en piel normal y su rol crítico en la cicatrización de heridas sugiere que la aplicación de las MSC exógenas podría ser una solución prometedora para tratar heridas no cicatrizantes en casos de traumas, diabetes, insuficiencia vascular, entre otras condiciones.

\section{Mecanismos de MSC en la cicatrización de heridas}

La cicatrización normal de una herida es un proceso dinámico y complejo que involucra una serie de eventos coordinados en el que se produce sangrado y coagulación, inflamación aguda, migración celular, proliferación, diferenciación, angiogénesis, reepitelización, síntesis y remodelación de matriz extracelular (MEC). Estos eventos se desarrollan en tres fases que se sobreponen: inflamación, proliferación y remodelación ${ }^{(34)}$.

Existe un vínculo entre las enfermedades por envejecimiento y el deterioro asociado a la cicatrización de heridas. En el caso de heridas crónicas, el progreso normal de estas fases es defectuoso, esto conduce a un daño tisular que no se repara en un período usual de tiempo. Estas manifestaciones pueden hallarse en casos de diabetes, hipertensión, insuficiencia vascular, quemaduras y vasculitis; otros factores como: infección, hipoxia, necrosis, exudados, y elevados niveles de citoquinas inflamatorias, contribuyen con la alteración de estos procesos.

Las MSC atenúan directamente la respuesta inflamatoria, disminuyendo la producción de citoquinas proinflamatorias (TNF- $\alpha$ e IFN- $\gamma$ ) y elevando los niveles de producción de citoquinas antiinflamatorias (IL10 e IL-4) convirtiéndolas, de este modo, en células beneficiosas para el tratamiento de heridas crónicas ${ }^{(34)}$. Este microambiente rico en IL-10 e IL-4, en este caso generado por las MSC, direcciona los macrófagos a un perfil M2, de naturaleza antiinflamatoria. Mientras la capacidad de diferenciación contribuye regenerando el tejido dañado, la señalización paracrina regula la respuesta celular en el microambiente de la lesión, esto reduce la inflamación, estimula la angiogénesis e induce la migración y proliferación celular ${ }^{(36)}$.

Varios estudios indican que distintos tipos celulares, tales como células epiteliales, células endoteliales, queratinocitos y fibroblastos, responden adecuadamente a la señalización paracrina de las MSC, regulando (activando o inhibiendo) diferentes respuestas celulares y activando la expresión de genes de moléculas reparadoras. La capacidad de las MSC para promover la transición desde la fase inflamatoria hacia la fase proliferativa, es particularmente crítica para el tratamiento de la herida, donde los elevados niveles de inflamación impiden la cicatrización ${ }^{(34)}$.

Las MSC también secretan mitógenos que estimulan la proliferación de queratinocitos, fibroblastos dérmicos y células endoteliales in vitro. Se ha mostrado que los fibroblastos dérmicos incrementan la secreción de colágeno tipo I en respuesta a las señales paracrinas de las MSC a través de la secreción de VEGF y HGF y manteniendo el balance entre TGF- $\beta 1$ y TGF- $\beta 3$.

EI TGF- $\beta$ es también liberado por plaquetas y macrófagos que ayuda a reclutar monocitos en la zona de la lesión y en el microambiente, estimula su maduración, incrementa la producción de componentes de la matriz extracelular: colágeno, proteoglicanos, fibronectina, y disminuye, a su vez, la secreción de proteasas responsables de la degradación de la propia matriz, estimulando la producción del inhibidor tisular de metaloproteinasas (TIMP). Los macrófagos proporcionan un depósito abundante de factores de crecimiento tisular (TGF- $\beta$, EGF, PDGF, y FGF) y citoquinas proinflamatorias (IL-1 e IL-6) que activan queratinocitos, fibroblastos y células endoteliales. Esto es llevado a cabo durante la fase inflamatoria y proliferativa ${ }^{(35-37)}$.

La duración de la fase de maduración depende de una serie de variables, incluyendo genética del paciente, edad, localización de la herida, tipo de lesión, y período de la inflamación. Durante esta fase el colágeno de tipo III (que es frecuente durante proliferación) se degrada y se sustituye gradualmente por colágeno tipo I. La remodelación del colágeno es necesaria para la 
transición desde tejido de granulación de la cicatriz, basada en la síntesis continua y la degradación del colágeno. Cuando el equilibrio entre la síntesis de colágeno y la degradación se consigue, comienza la maduración de la herida ${ }^{(37)}$.

La degradación del colágeno en la herida se controla por varias metaloproteinasas de la matriz, que son secretadas por macrófagos, células epidérmicas, células endoteliales y fibroblastos. Durante la remodelación tisular, el PDGF ayuda a romper el colágeno inicial de la matriz hasta la remodelación. Otros factores de crecimiento que cumplen un papel en el proceso de remodelación son TGF- $\beta$ y FGF.

En síntesis, la cicatrización es un proceso complejo que requiere una coordinada interrelación entre la matriz extracelular, factores de crecimiento y células. Las MSC tienen una participación importante en cada fase del proceso reparativo ya mencionados. Las MSC son una fuente atractiva para conducir y mejorar las terapias de cicatrización de heridas particularmente crónicas o quemaduras (Figura 1).

\section{Fuentes de las células tronco mesenquimales}

Las MSC fueron aisladas por primera vez a partir de médula ósea en 1976 por Friedenstein et al. ${ }^{(38,39)}$ quienes la describieron como células de aspecto fibroblástico con adherenciaal plástico, capaces de sercultivadas sin modificar su fenotipo. Caplan, en 1991, fue el primero en denominar a estas células como células tronco mesenquimales humanas y las definió por su capacidad de adherencia, proliferación ex vivo y capacidad de diferenciarse a múltiples células de

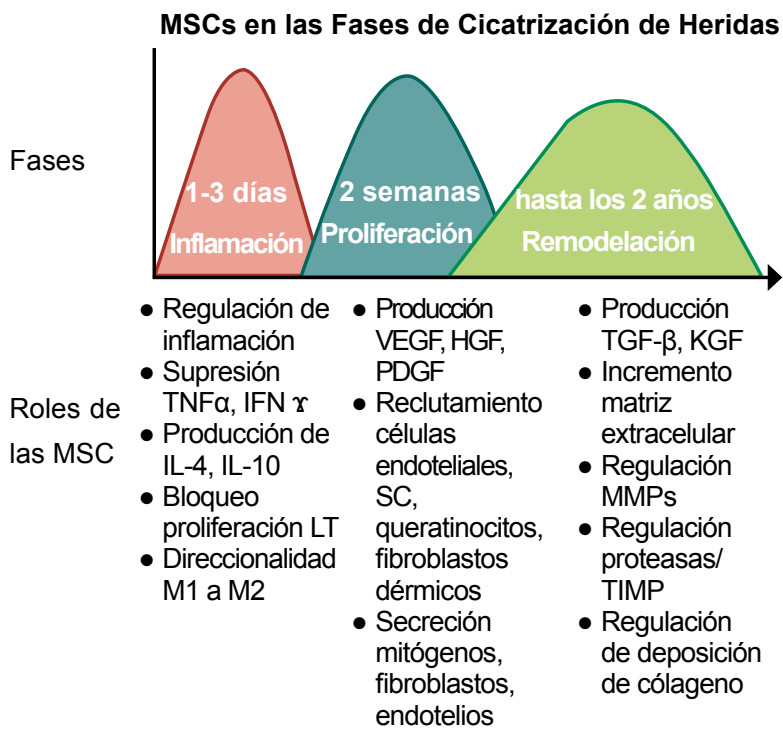

Figura 1. Rol de las células troncales mesenquimales (MSC) durante cada fase del proceso de cicatrización de herida (Adaptado y modificado de: Maxson, Lopez, Yoo et al. MSC in Wound Repair. Stem Cells Translational Medicine 2012;1:142-149) origen mesodérmico ${ }^{(40)}$. Las MSC se aislaron inicialmente de la médula ósea donde se encuentran en una cantidad muy reducida, alrededor del $0,003 \%$ del total de células mononucleares ${ }^{(41)}$. Otros tejidos donde se ha encontrado MSC es la sangre y tejido de cordón umbilical, tejidos fetales, tejidos placentarios, líquido amniótico, pulpa dental, entre otros, dentro de los cuales ha destacado el tejido adiposo como una fuente rica y muy accesible ${ }^{(42-48)}$. La primera vez que se demostró la existencia de las MSC en el estroma del tejido adiposo fue en el año 2000 por Gimble et al. quienes describieron la capacidad in vitro de estas células de diferenciarse a tejidos osteogénicos y mineralizar una matriz extracelular cuando se les exponía a diferentes factores, demostrando así la capacidad multipotencial ${ }^{(49)}$. La confirmación definitiva se dio en el año 2001 por Hedrick et al. quienes describieron a las MSC derivadas de tejido graso subcutáneo como células homogéneas con aspecto fibroblástico, obtenidas a partir de la fracción vascular estromal del tejido adiposo con capacidad de diferenciarse a osteocitos, condrocitos y adipocitos; además, analizaron su cinética de desarrollo y los marcadores de superficie, llegando a la conclusión de que eran muy similares a las MSC aisladas de médula ósea ${ }^{(49,50)}$.

\section{Cultivo y expansión celular de MSC de tejido adiposo humano}

\section{Muestras de tejido adiposo}

La obtención de la muestra de tejido puede ser a partir de lipoaspirados estéticos, abdominoplastías o una intervención quirúrgica, de donde se puede obtener $5 \mathrm{~g}$ de tejido adiposo aproximadamente, que son suficientes para iniciar un proceso de cultivo celular primario, con fines de investigación. La muestra debe colocarse inmediatamente en un frasco estéril con medio de cultivo o buffer fosfato salino (PBS) con antibióticos y transportado al laboratorio en un ambiente de $4-8{ }^{\circ} \mathrm{C}$ dentro de las $24 \mathrm{~h}$ siguientes ${ }^{(50)}$

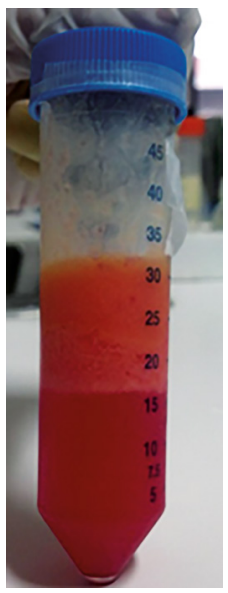

Figura 2. Muestra de lipoaspirado en medio de transporte. Se observa una zona superior amarilla compuesta por el tejido adiposo (Fuente: Laboratorio de Inmunología LID-108-UPCH) 


\section{Obtención de la fracción estromal vascular (FEV)}

La muestra de tejido adiposo es lavada con PBS estéril $(\mathrm{pH} 7,4) 3$ veces a $1500 \mathrm{rpm}$ por $10 \mathrm{~min}$ a $22-24^{\circ} \mathrm{C}$. Luego se procede a incubar con colagenasa tipo I al $0,1 \%$ a 37 ${ }^{\circ} \mathrm{C}$ en constante agitación por $60 \mathrm{~min}$. Seguidamente, se detiene la reacción adicionando el medio de cultivo a-MEM con antibióticos (1\% penicilina/estreptomicina), en un volumen igual al de la digestión. Luego se filtra (100 $\mu \mathrm{m})$ y se procede a realizar dos lavados respectivos con el medio, centrifugando a $2000 \mathrm{rpm} \times 10$ ', obteniéndose al final un pellet celular conocido como FEV que es rico en MSC. El pellet celular es resuspendido en $1 \mathrm{~mL}$ de medio completo ( $\alpha-M E M+1 \% \mathrm{P} / \mathrm{S}+15 \%$ lisado plaquetario humano). El lisado plaquetario se utiliza como sustituto del suero bovino fetal (SBF) y es preparado de acuerdo a protocolos ya establecidos.

\section{Cultivo y expansión de las MSC}

La FEV es cultivada en flask de $25 \mathrm{~cm}^{2}$ con medio a-MEM completo e incubado a $37{ }^{\circ} \mathrm{C}$ en $5 \% \mathrm{CO}_{2}$ por 72 $\mathrm{h}$, apreciándose pocas células de aspecto fibroblástico adheridas al flask, junto a otras células no adheridas (Figura 3). Luego se cambia el medio con la finalidad de retirar las células no adherentes. Se cambia el medio cada 2 a 3 días hasta alcanzar confluencia de $70-80 \%$ de las células adherentes (Figura 4). Luego se procede a realizar la tripsinización (tripsina EDTA $0,25 \%)$ y se vuelve a subcultivar las células en flask de $75 \mathrm{~cm}^{2}$ en razón de 5000-10000 células por $\mathrm{cm}^{2}$. En el pasaje 3 se obtienen las células para su identificación, criopreservación y experimentación. Para aplicación terapéutica se recomienda usar células en el cuarto pasaje como máximo.

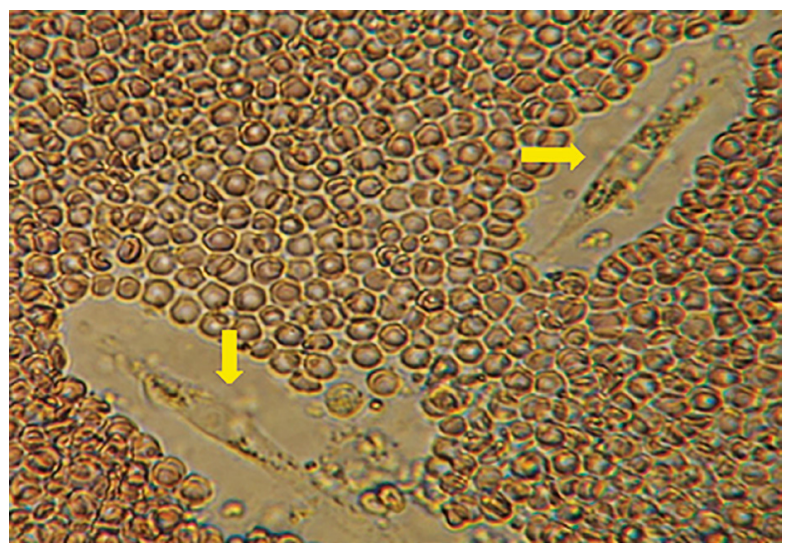

Figura 3. Células en fondo del flask luego de $72 \mathrm{~h}$ de cultivo (microscopia invertida-100X). Con la flecha se indican las células con características de células troncales mesenquimales. Las demás células circundantes corresponden a leucocitos y hematíes provenientes de la muestra de tejido adiposo (Fuente: Laboratorio de Inmunología LID-108-UPCH)

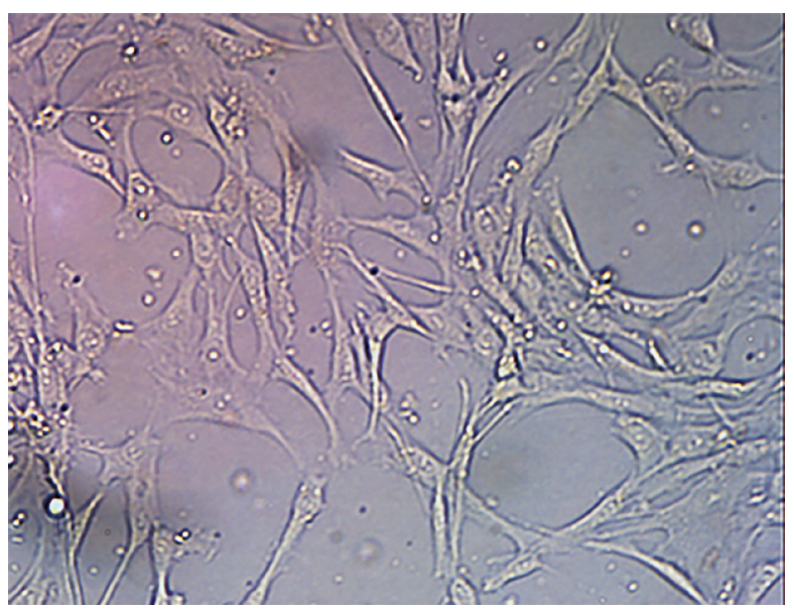

Figura 4. Células adheridas en flask de cultivo con característica de células troncales mesenquimales con una confluencia del $70 \%$. (microscopia invertida-100X). Presentan aspecto fibroblástico (Fuente: Laboratorio de Inmunología LID108-UPCH)

\section{Identificación fenotípica}

La ISCT (Sociedad Internacional de Terapia Celular) estableció en el 2006 los criterios de identidad mínima para las MSC ${ }^{(51)}$. En función a ello, las MSC, después de un proceso de cultivo deben de identificarse a través de marcadores de membrana usando para tal fin la citometría de flujo. Deben ser positivos en más o igual al 98\% para CD73, CD90, CD105 y negativos en menos o igual al $2 \%$ para CD45, CD34, HLA-DR, CD14 o CD11b, CD79a o CD19 (Figura 5).

\section{Identificación funcional}

Está basado en la capacidad de diferenciación que tienen las MSC hacia condrocitos, adipocitos y osteoblastos que fueron establecidos por el consenso de la ISCT. En el pasaje 3 del cultivo se subcultivan las células en placas de 12 pozos con el medio de diferenciación específico para cada linaje. Luego de un tiempo de cultivo las células muestran morfologías diferentes a la inicial (Figura 6), las que se confirmarán con coloraciones específicas, siendo las más usadas el oil red para adipogénesis, alcian blue para condrogénesis $y$ fosfatasa alcalina para osteogénesis.

\section{APLICACIONES TERAPÉUTICAS DE CÉLULAS TRONCO MESENQUIMALES}

Las aplicaciones terapéuticas de las MSC están creciendo constantemente y se está convirtiendo en una alternativa para diversas formas de aplicaciones tanto clínicas, como de investigación. Para el 08 de agosto de 2016, al buscar publicaciones en Medline con el encabezamiento Stem Cells, se encuentran 258979 artículos registrados, 


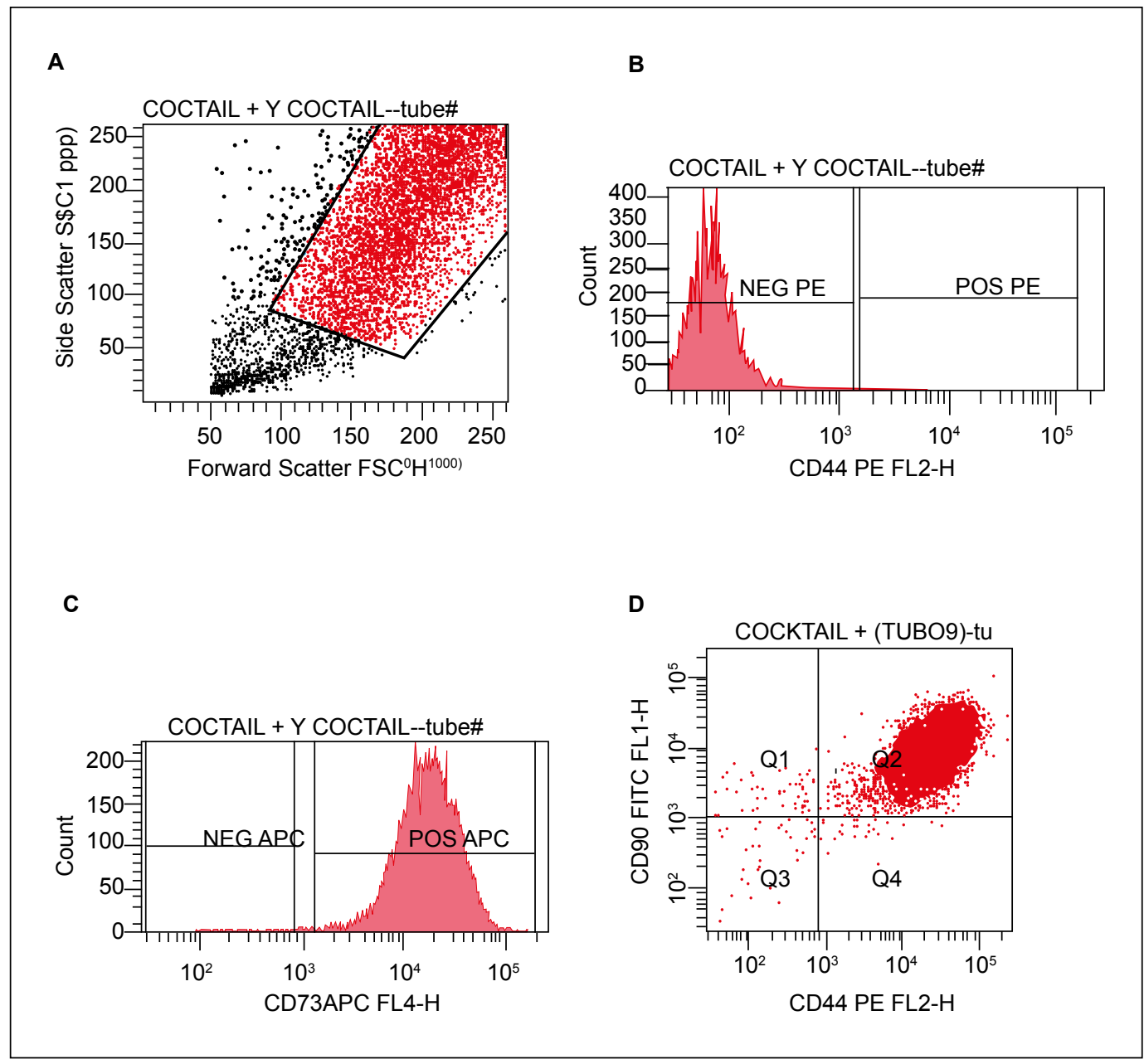

Figura 5. Evaluación por citometría de flujo de los marcadores negativos y positivos de las células troncales mesenquimales. A) Selección por tamaño y granularidad de la población celular obtenida del cultivo; B) Evaluación de la expresión de los marcadores negativos; C) Evaluación de la expresión del marcador CD73, positivo para células troncales mesenquimales; D) Evaluación de la expresión de los marcadores positivos CD90 y CD44 (Fuente: Laboratorio de Inmunología LID-108-UPCH)

mientras con el encabezamiento Mesenchymal Stem Cells, se encuentran 42164 artículos, lo cual muestra el gran interés científico en este tema y en sus potenciales aplicaciones terapéuticas.

Uno de los puntos clave para la potencial utilidad de las MSC es que se podrían utilizar en forma autóloga o alogénica (autóloga: MSC del mismo individuo; alogénica: MSC de otro individuo de la misma especie). Esto es debido, como se ha mencionado previamente, a la característica de las MSC de no expresar MHC clase II ni móleculas co-estimuladoras y baja expresión de MHC clase I. Esta característica ha atraído la atención, por la posibilidad de la comercialización en forma farmacéutica de preparados de MSC. Aunque, para determinadas condiciones, deberán de ser preferencialmente autólogas.

Una de las principales características que son vistas con mucho interés es la capacidad inmunomoduladora de las MSC. Y esta capacidad inmunomoduladora está importantemente influenciada por el microambiente en el que se encuentren.

Prácticamente cada especialidad médica ha encontrado la posibilidad de uso de MSC. Las clásicas aplicaciones en trasplante de médula ósea o la construcción de piel artificial para quemados, han sido desbordados por su uso como terapia regenerativa o reconstructiva para cualquier órgano o tejido corporal.

Inicialmente, su utilidad se creyó, preferencialmente, se debía a su capacidad de transdiferenciación tisular; sin embargo, posteriormente, diferentes estudios han reconocido como su principal capacidad la producción de factores paracrinos y endocrinos a través de la secreción de productos mitogénicos celulares, antiapoptóticos, antiinflamatorios, antifibróticos y angiogénicos. 


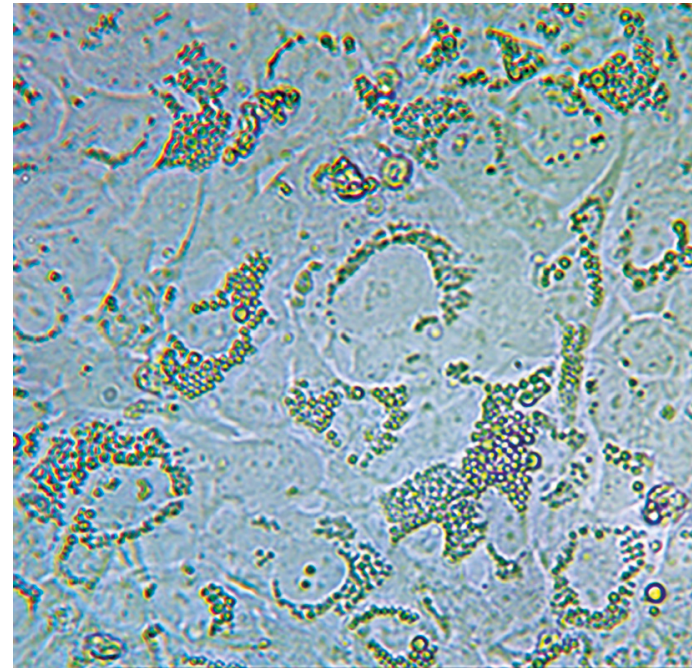

Figura 6. Células troncales mesenquimales en proceso de diferenciación adipogénica (microscopia invertida-100X). Se observan vacuolas de grasa brillantes dentro de los citoplasmas de las células adheridas en el flask de cultivo con medio de diferenciación STEMPRO® Adipogénesis. (Fuente: Laboratorio de Inmunología LID-108-UPCH)

Igualmente, como ha sido revisado por Engela et al. ${ }^{(52)}$ la inducción o atracción de linfocitos T reguladores hacia el tejido donde son colocadas, parece crucial en la función y la persistencia a largo plazo del efecto inmunorregulador y reparador de la aplicación de MSC.

Sin embargo, a pesar de esta situación prometedora, estudios experimentales han mostrado que no todas las condiciones clínicas pueden ser favorecidas por esta terapia. Seifert et al. ${ }^{(53)}$ evaluaron el tratamiento con MSC de un modelo preclínico de trasplante de riñón, encontrando incremento en la respuesta inmune humoral, los signos de inflamación y rechazo de tejido en los dos grupos tratados con MSC provenientes del donador y del receptor, comparado con el control que no recibió MSC.

Claramente, el efecto inmunorregulador de las MSC está regulado, en parte, por el microambiente en el cual sean colocadas. Leijs et al. ${ }^{(54)}$ mostraron que el líquido sinovial de pacientes con enfermedades inflamatorias articulares moduló la activación de genes con actividad inmunorreguladora de MSC. Igualmente, De la Rosa et al. ${ }^{(55)}$ mostraron que la activación de Toll-Like Receptors (TLRs) inducida por estructuras de patógenos (pathogen associated molecular patterns, PAMPs) o señales de peligro tisular (Damage associated molecular patterns, DAMPs) modularon la expresión de un fenotipo pro- o antiinflamatorio en las MSC.

Por lo tanto, entender el impacto a nivel molecular y celular, y sus interacciones con el microambiente tisular específico, es muy importante para lograr resultados favorables en la terapia con MSC.

\section{APLICACIONES EVALUADAS EN CONDICIONES CLÍNICAS ESPECÍFICAS: TERAPIA CON MSC EN ENFERMEDADES CARDIACAS}

En el ámbito de enfermedades cardiovasculares, se ha utilizado diversas fuentes de células estromales. Una de las fuentes iniciales han sido las MSC. Sin embargo, el descubrimiento de las iPSCs y cardiomiocitos derivados de iPSCs (iPSC-CMs) han incentivado el uso de estas otras fuentes de células madre y sus aplicaciones a patologías humanas, sin embargo, estas nuevas formas de Stem cells no es tema de nuestra revisión actual.

Durante y luego de un infarto de miocardio, la fase temprana se caracteriza por un microambiente local con inflamación, apoptosis y necrosis. Más tardíamente sucede una expansión del tejido infartado hacia la pared miocárdica, reclutamiento de células mieloides, presencia de tejido necrótico y degradación de la matriz extracelular, subsecuente angiogénesis y remodelación del ventrículo, que incluye formación de cicatrices, expansión hipertrófica de los cardiomiocitos y fibrosis, llevando a dilatación del ventrículo izquierdo, frecuentes arritmias e insuficiencia cardiaca. La capacidad endógeno cardiaca de regeneración, a partir de célula progenitoras cardiacas es limitada ${ }^{(56)}$.

La terapia con MSC adultas en pacientes con infarto de miocardio ha mostrado resultados bastante alentadores ${ }^{(57,58)}$. Las MSC derivadas de médula ósea o de tejido adiposo se han evaluado en varios estudios en animales experimentales con infarto miocárdico inducido. Entre otros estudios, Silva et al. (59) indujeron infarto por oclusión arterial en perros, y 30 días después aplicaron $5 \times 10^{6} \mathrm{MSC}$ intramiocárdicas obtenidas de médula ósea, observando mejora de parámetros hemodinámicos, incremento de angiogénesis y menor fibrosis cardiaca. Del mismo modo, Miyahara et al. ${ }^{(60)}$ indujeron infarto por oclusión arterial en ratas, y cuatro semanas después aplicaron $8 \times 10^{6}$ MSC logrando disminución de la mortalidad, mejora de los parámetros hemodinámicos y cierta regeneración cardiaca.

En estudios clínicos se ha avanzado poco con el uso de MSC. En un estudio clínico llamado POSEIDON, Hare et al. (61) evaluaron 31 pacientes con infarto miocárdico, utilizando MSC en 3 dosis diferentes de 20 a $200 \times 10^{6}$ células administradas intramiocárdicamente transendocardial, observando mejora en el rendimiento físico y disminución del volumen diastólico residual final en el ventrículo izquierdo. 


\section{TERAPIA CON MSC EN ENFERMEDAD HEPÁTICA TERMINAL}

La cirrosis hepática es caracterizada por necrosis de hepatocitos, distorsión de la estructura hepática y formación de nódulos regenerativos. Inicialmente se demostró que fetos humanos desde las 10 a 18 semanas de vida contenían gran cantidad de SC hepáticas con capacidad bidiferencial, convertirse en células de ductos biliares y convertirse en hepatocitos. Desde los inicios de los 80 la terapia con hepatocitos fetales se ofreció como una alternativa interesante. Se evaluaron las rutas de inoculación de células hepáticas vía intraesplénica, intraportal o intraperitoneal, resultando el trasplante de células hepáticas intraperitoneal la más ventajosa en modelos animales. En 1992 se realizó el primer trasplante exitoso de hepatocitos fetales en humanos, que mostró resultados aceptables. Sin embargo, a pesar de que ha habido varios reportes exitosos posteriores con esta técnica, no se ha generalizado su uso. La terapia con SC hepáticas ha generado una alternativa prometedora en caso de enfermedad hepática crónica terminal ${ }^{(62)}$.

Varios estudios han demostrado la generación de SC hepáticas (HSC) a partir de tejido hepático adulto, seguido de proliferación y diferenciación en hepatocitos funcionales. Dos fuentes de SC se han evaluado para esta terapia regenerativa: MSC provenientes de cordón umbilical o aspirado de médula ósea y las iPSC derivadas de otras células somáticas. Se revisará solo lo avanzado con el uso de MSC.

Adicionalmente, la potencialidad del crecimiento de HSC a partir de cualquiera de las fuentes de SC mencionadas, incluyendo MSC, en constructos de órganos tridimensionales, se ha convertido en una estrategia terapéutica prometedora. Es conocido que los hepatocitos y toda su infraestructura vascular está soportada en base a contacto célula a célula y al contacto con la matriz extracelular particular. De tal manera que se está desarrollando interesantemente la bioingeniería de tejidos con construcción de matrices naturales tridimensionales como soporte para el crecimiento de las SC.

Se están evaluando otras fuentes de obtención de MSC, por ejemplo, Shi et al. ${ }^{(63)}$ han reportado la obtención de MSC a partir de folículo piloso. Sin embargo, no lograron la transformación a células parecidas a hepatocitos, lo cual sí hicieron cuando usaron MSC derivadas de folículo piloso, pero trasformadas en células pluripotentes inducidas (iPS) obtenidas igual a partir de folículo piloso. Igualmente, Wang et al. ${ }^{(64)}$ han aislado MSC de tejido hepático, con algunas ventajas funcionales comparadas a las MSC obtenidas de otras fuentes.

\section{TERAPIA CON MSC EN ÚLCERAS CRÓNICAS DE PIEL}

Otra aplicación evidente es referida a la cicatrización de heridas en condiciones desfavorables. Una revisión de Chen et al. ${ }^{(65)}$, mostraron que la aplicación de MSC produjo mejora de la reparación tisular al aminorar la inflamación local, mejorar la reepitelización, la formación de tejido de granulación y la neovacularización, aun en condiciones de sufrimiento tisular, como el caso de diabetes.

Muchos estudios, tanto en animales experimentales como en humanos, han demostrado repetidamente el efecto beneficioso en curación de heridas de piel con el uso de MSC ${ }^{(66,67)}$. El uso de roedores ha sido importante para evaluar el uso de MSC para mejora de cicatrización de heridas crónicas. Sin embargo, es claro que hay diferencias estructurales entre la piel de roedor y la humana. La piel de roedores carece de glándulas sudoríparas apocrinas y crestas epiteliales en la papila dérmica, sin embargo, las crestas epiteliales pueden aparecer en el roedor durante el proceso de cicatrización de heridas ${ }^{(66)}$. Especialmente los modelos murinos de diabetes han sido de utilidad en experimentos de reparación de heridas crónicas con uso de MSC. La diabetes mellitus (DBM) con cierta frecuencia ocasiona úlceras crónicas que no cicatrizan debido a una conjunción de fenómenos como isquemia local, lesión por reperfusión tisular, infección bacteriana, deficiencia en el aporte de células de renovación y disminución de cantidad y respuesta disminuida a factores de crecimiento y otras moléculas reparadoras tisulares por senescencia, resultando en procesos inflamatorios crónicos y deficiente cicatrización.

Sin embargo, aún hay escasas investigaciones en humanos en este proceso reparativo. Un estudio realizado el 2003 por Badiavas y Falanga (68) utilizó MSC cultivadas a partir de médula ósea autóloga, administradas inicialmente en forma subcutánea y luego en forma tópica, logrando incremento en la reorganización de la piel, neoangiogénesis y cierre total de las heridas. Otros estudios han utilizado también MSC obtenidas de cordón umbilical o médula ósea, por administración subcutánea y/o tópica en úlceras diabéticas o producidas por procesos vasculíticos, observando resultados favorables en la cicatrización de heridas crónicas, mejorando consecuentemente otros índices de calidad de vida, como la distancia de caminata sin dolor ${ }^{(67)}$.

Otro evento necesario en la reparación de heridas es la formación de vasos sanguíneos que provean de nutrientes y factores paracrinos a la zona. Las MSC han demostrado formar neovascularización a través de vasculogénesis. Como previamente se mencionó, 
las MSC producen factores paracrinos reparadores tisulares. VEGF, EGF, factor de crecimiento estromal derivado de células tipo 1 alfa (SCDGF-1a, stromal cell-derived growth factor 1 alfa), eritropoyetina y otros factores solubles han sido demostrados en presencia de MSC.

\section{TERAPIA CON CÉLULAS TRONCO MESENQUIMALES EN OSTEOARTROSIS}

La osteoartrosis $(\mathrm{OA})$ es una condición degenerativa del cartílago articular que conlleva daño progresivo estructural y funcional del cartílago y una serie de mecanismos compensatorios de todos los componentes del sistema articular, principalmente del hueso subcondral; estructuras intraarticulares, como sinovia articular y ligamentos; extraarticulares, como tendones, y deterioro secundario de estructuras musculares $y$, consecuentemente, limitación funcional progresiva.

Existen una serie de factores de riesgo para el desarrollo de OA, algunos inmodificables como son la edad avanzada, pero otros modificables con medidas preventivas de salud pública como el sobrepesoobesidad, disturbios metabólicos como la diabetes, hiperlipidemias o el síndrome metabólico, pero que son difíciles de controlar a nivel poblacional mientras no exista un consenso en diferentes ámbitos de la sociedad para eliminar estos flagelos de la sociedad.

Las terapias convencionales no están bien desarrolladas, disponiéndose solo de terapias farmacológicas para calmar los síntomas molestos de la condición, pero que no cambian el curso de la enfermedad. Algunos productos terapéuticos se han desarrollado, como glucosamina y otros, pero que han mostrado resultados controversiales respecto a sus efectos beneficiosos a largo plazo.

Las terapias con MSC han mostrado resultados alentadores en modelos animales y en pocos estudios clínicos humanos, debido a su capacidad de disminuir la respuesta inflamatoria, sus mecanismos inductores, y su capacidad regenerativa por los factores reparadores y factores de crecimiento que secretan las MSC, como ya se ha mencionado ${ }^{(68)}$. De hecho, se ha observado que en OA hay una disminución de las MSC estromales y las existentes tienen una menor capacidad proliferativa y de diferenciación (68).

Centeno et al. demostraron mejoras en el volumen de cartílago y volumen de meniscos luego de la combinación de uso de MSC provenientes de médula ósea (MO) y lisado plaquetario, pero en un número pequeño de casos ${ }^{(70)}$. En todo caso, el plasma rico en plaquetas potencialmente podría mejorar la migración celular, proliferación y diferenciación de las SC locales ${ }^{(71)}$.

Jo et al evaluaron 18 pacientes con osteoartrosis de rodilla que recibieron MSC obtenidas de tejido adiposo en dosis de $1 \times 10^{7}, 5 \times 10^{7}$ y $1 \times 10^{8}$ células intraarticulares y nueve pacientes adicionales que recibieron la dosis mayor. Todos los pacientes tuvieron mejoría sintomática del dolor y función evaluada por WOMAC (The Western Ontario and McMaster Universities Arthritis Index), no tuvieron efectos adversos y logró evidenciarse disminución del defecto del cartílago demostrada por artroscopia e histología ${ }^{(72) .}$

La fuente de obtención de MSC es crucial para los resultados observados. Una fuente de MSC usada con cierta frecuencia en la práctica clínica habitual ha sido obtener MSC autólogas a partir de aspirado de MO y posterior separación de células mononucleares (bone marrow mononuclear cells, BMMC). Sin embargo, estudios de Peng et al. ${ }^{(73)}$, Álvarez-Viejo et al. y Kern et al. (73-75) han mostrado resultados concluyentes: la obtención de MSC de BMMC proporciona 0,001 a 0,02\% del total de células, mientras las MSC obtenidas a partir de aspirado de tejido adiposo proporciona 1 a $7 \%$ del total de células obtenidas, con buena capacidad condrogénica y de liberación de factores de crecimiento ${ }^{(75)}$.

Un estudio recientemente publicado por Pers et al. del estudio ADIPOA ${ }^{(76)}$ utilizó MSC autólogas obtenidas a partir de aspirado de tejido adiposo en pacientes con OA severa sintomática de rodillas, administrados en una sola dosis por inyección transcutánea intraarticular, en un estudio clínico fase I. Encontraron que el método fue seguro con ausencia de eventos adversos serios y después de 6 meses de seguimiento un porcentaje de los pacientes mostró mejoría del dolor y función articular comparados al momento inicial.

\section{CONCLUSIÓN}

Todos los factores discutidos en esta revisión son de notable importancia y se requiere individualizar su rol en los mecanismos de mejora de procesos patológicos prevalentes en humanos, por ejemplo: la recuperación de heridas crónicas.

Conflictos de interés: los autores declaran no tener conflictos de interés en la publicación de este artículo.

Fuentes de financiamiento: Proyecto INNOVATE PERÚ. Código: PIAP-3-P-740-14

Contribuciones de autoría: ILR, WC y JA han participado en la concepción del artículo y aprobación de la versión final GV SJ, MP, DA,MC la recolección de datos, su redacción. 


\section{REFERENCIAS BIBLIOGRÁFICAS}

1. Prósper F, Gavira J, Herreros J, Rábago G, Luquin R, Moreno J et al. Trasplante celular y terapia regenerativa con SC. Anal Sist Sanit Navar 2006;29:219-34.

2. Bajada S, Mazakova I, Richardson JB, Ashammakhi N. Updates on stem cells and their applications in regenerative medicine. J Tissue Eng Regen Med 2008;2:169-83.

3. Brunt K, Weisel RD, Li RK. Stem cells and regenerative medicine future perspectives. Can J Physiol Pharmacol 2012;90:327-35

4. Plomer A, Taymor KS, Scott CT. Challenges to human embryonic stem cell patents. Stem Cell 2008;2:13-7.

5. Evans M, Kaufman M. Establishment in culture of pluripotential cells from mouse embryos. Nature 1981;292:1546.

6. Thomson J. Funding of human embryo research in the US. Nat Biotechnol. 1999,17:312.

7. Serafini M, Verfaillie CM. Pluripotency in Adult Stem Cells: State of the Art. Semin Reprod Med 2006;24:379-88. Review.

8. Taoudi S, Gonneau C, Moore K, et al. Extensive hematopoietic stem cell generation in the AGM region via maturation of VE-cadherin+CD45+ pre-definitive HSCs. Cell Stem Cell 2008;3:99-108

9. Matsa E, Sallam K, Wu JC. Cardiac stem cell biology: glimpse of the past, present, and future. Circ Res 2014;114:21-7

10. Monti M, Perotti C, Del Fante C, Cervio M, Redi CA; Fondazione IRCCS Policlinico San Matteo, Pavia (Italia). Stem cells: sources and therapies. Biol Res 2012;45:207-14

11. Yong KW, Wan Safwani WK, Xu F, Wan Abas WA, Choi JR, PingguanMurphy B. Cryopreservation of Human Mesenchymal Stem Cells for Clinical Applications: Current Methods and Challenges. Review. Biopreserv Biobank 2015;13:231-9.

12. Gnecchi M, Danieli P, Malpasso G, Ciuffreda MC. Paracrine Mechanisms of Mesenchymal Stem Cells in Tissue Repair. Methods Mol Biol 2016;1416:123-46

13. Wang $Y$, Wang $D$, Guo D. MiR-124 Promote Neurogenic Transdifferentiation of Adipose Derived Mesenchymal Stromal Cells Partly through RhoA/ROCK1, but Not ROCK2 Signaling Pathway. PLoS One 2016;11:e0146646.

14. Roman-Blas JA, Bizzi E, Largo R, Migliore A, Herrero-Beaumont G. An update on the up and coming therapies to treat Osteoarthritis, a multifaceted disease. Expert Opin Pharmacother 2016 Jun 21 [Epub ahead of print]

15. Roncalli J. An update on primary findings and new designs in biotherapy studies for acute myocardial infarction. Future Cardiol 2014;10:781-8.

16. Hinden L, Shainer R, Almogi-Hazan O, Or R. Ex Vivo Induced Regulatory Human/Murine Mesenchymal Stem Cells as Immune Modulators. Stem Cells 2015;33:2256-67.

17. Haddad R, Saldanha-Araujo F. Mechanisms of T-Cell Immunosuppression by Mesenchymal Stromal Cells: What Do We Know So Far?. Biomed Res Int 2014;2014:216806 doi: 10.1155/2014/216806. Epub 2014 Jun 16. Review.

18. Cerón W. Capítulo 16. Células Madre e Inmunomodulación. En: Aguilar JL. Bases de la Inmunología Clínica. Ed. Sociedad Peruana de Inmunología. Lima, Perú. 2013.

19. Fayyad-Kazan H, Faour WH, Badran B, Lagneaux L, Najar M. The immunomodulatory properties of human bone marrow-derived mesenchymal stromal cells are defined according to multiple immunobiological criteria. Inflamm Res 2016;65:501-10.

20. Waterman RS, Tomchuck SL, Henkle SL, Betancourt AM. A new mesenchymal stem cell (MSC) paradigm: polarization into a pro-inflammatory MSC1 or an Immunosuppressive MSC2 phenotype. PLoS One 2010 Apr 26;5(4):e10088. doi: 10.1371/journal.pone.0010088.

21. Tomchuck SL, Zwezdaryk KJ, Coffelt SB, Waterman RS, Danka ES, et al. Tolllike receptors on human mesenchymal stem cells drive their migration and immunomodulating responses. Stem Cells 2008;26:99-107.

22. Ma S, Xie N, Li W, Yuan B, Shi Y, Wang Y. Immunobiology of mesenchymal stem cells. Cell Death Differ 2014;21:216-25.

23. Fan L, Hu C, Chen J, Cen P, Wang J, Li L. Interaction between Mesenchymal Stem Cells and B-Cells. Int J Mol Sci. 2016 May 5;17(5). pii: E650. doi: 10.3390/ ijms 17050650 .
24. Đokić JM, Tomić SZ, Čolić MJ. CrossTalk Between Mesenchymal Stem/ Stromal Cells and Dendritic Cells. Curr Stem Cell Res Ther 2016;11:51-65.

25. Ramasamy R, Fazekasova H, Lam EW, Soeiro I, Lombardi G and Dazzi F. Mesenchymal stem cells inhibit dendritic cell differentiation and function by preventing entry into the cell cycle. Transplantation 2007;83:71-76.

26. Selleri S, Bifsha P, Civini $S$, et al. Human mesenchymal stromal cellsecreted lactate induces M2macrophage differentiation by metabolic reprogramming. Oncotarget 2016 Apr 6 . doi: 10.18632/oncotarget.8623. [Epub ahead of print]

27. Almeida CR, Caires HR, Vasconcelos DP, Barbosa MA. NAP-2 Secreted by Human NK Cells Can Stimulate Mesenchymal Stem/Stromal Cell Recruitment. Stem Cell Reports 2016;6:466-73.

28. Selmani Z1, Naji A, Zidi I, et al. Human leukocyte antigen-G5 secretion by human mesenchymal stem cells is required to suppress $\mathrm{T}$ lymphocyte and natural killer function and to induce CD4+CD25highFOXP3+ regulatory T cells. Stem Cells 2008;26:212-22.

29. Chen PM, Liu KJ, Hsu PJ, Wei CF, Bai $\mathrm{CH}, \mathrm{Ho} \mathrm{LJ}$, et al. Induction of immunomodulatory monocytes by human mesenchymal stem cell-derived hepatocyte growth factor through ERK1/2. J Leukoc Biol 2014;96:295303.

30. Yagi H, Soto-Gutierrez A, Parekkadan B, Kitagawa Y, Tompkins RG, Kobayashi $\mathrm{N}$, et al. Mesenchymal Stem Cells: Mechanisms of Immunomodulation and Homing. Cell Transplant 2010;19:667679.

31. Lee BC, Kim HS, Shin TH, Kang I, Lee JY, Kim JJ, et al. PGE2 maintains selfrenewal of human adult stem cells via EP2-mediated autocrine signaling and its production is regulated by cell-to-cell contact. Sci Rep 2016 May 27;6:26298. doi: 10.1038/srep26298.

32. Madrigal M, Rao KS, Riordan $\mathrm{NH}$. A review of therapeutic effects of mesenchymal stem cell secretions and induction of secretory modification by different culture methods. J Transl Med 2014; 12:260-74

33. Ungerer C1, Quade-Lyssy P, Radeke HH, Henschler R, Königs C, Köhl U, 
et al. Galectin-9 Is a Suppressor of T and B Cells and Predicts the Immune Modulatory Potential of Mesenchymal Stromal Cell Preparations. Stem Cells Dev 2014;23:755-66

34. Maxson S, Lopez EA, Yoo D, Danilkovitch-Miagkova A, Leroux MA. Concise review: role of mesenchymal stem cells in wound repair. Stem Cells Transl Med 2012;1:142-9.

35. Arno AI, Amini-Nik S, Blit PH, AlShehab M, Belo C, Herer E, et al. Human Wharton's jelly mesenchymal stem cells promote skin wound healing through paracrine signaling. Stem Cell Res Ther 2014;5:28.

36. Pelizzo G, Avanzini MA, Icaro-Cornaglia A, Osti M, Romano P, Avolio L, et al. Mesenchymal stromal cells for cutaneous wound healing in a rabbit model: pre-clinical study applicable in the pediatric surgical setting. J Transl Med 2015;13:219.

37. Kirby GTS, Mills SJ, Cowin AJ, Smith LE. Stem Cells for Cutaneous Wound Healing. Biomed Res Int 2015;2015:285869. doi: 10.1155/2015/285869. Epub 2015 Jun 2.

38. Friedenstein AJ,Gorskaja JF, KulaginaNN. Fibroblast Precursors in normal and irradiated mouse hematopoietic organs. Exp Hemat 1976;4:267-74.

39. Friedenstein AJ, Chailakhyan RK, Latsinik NV, Panasyuk AF, KeilissBorok IV. Stromal cells responsible for transferring the microenvironment of the hemopoietic tissues. Cloning in vitro and retransplantation in vivo. Transplantation 1974;17:331-40.

40. Caplan AI. Mesenchymal stem cells. J Orthop Res 1991;9:641-50.

41. Beyer N, Da Silva L. Mesenchymal Stem Cells: Isolation in vitro Expansion and Characterization. Handb Exp Pharmacol 2006; 174:249-82.

42. Ribeiro J, Pereira T, Amorim I, Caseiro AR, Lopes MA, Lima J, et al. Cell Therapy with Human MSC Isolated from the Umbilical Cord Wharton Jelly Associated to a PVA Membrane in the Treatment of Chronic Skin Wounds. Int J Med Sci 2014;1 1:979-87

43. Lee OK, Kuo TK, Chen WN, Lee $\mathrm{KD}$, Hsieh SL, Chen TH. Isolation of multipotent mesenchymal stem cells from umbilical cordon blood. Blood 2000;103:1669-75.

44. Campagnoli C, Roberts IA, Kumar S, Bennett PR, Bellantuono I, Fisk NM. Identification of mesenchymal stem/ progenitor cells in human first trimester fetal blood, liver and bone marrow. Blood 2001;98:2396-402.

45. Campagnoli C, Fisk NM, Overton T, Bennett P, Watts T, Roberts I. Circulating hematopoietic progenitor cells in first trimester fetal blood. Blood 2000;95:1967-72.

46. Anker PS, Scherjon SA, Klijburg-van der Keur GM, de Groot-Swings GM. Class FH, Fibbe WE, Kanhai HH. Isolation of mesenchymal stem cells of fetal or maternal origin from human placenta. Stem Cells 2004;22:1338-45.

47. Yen BL, Huang HI, Chien CC, Jui $\mathrm{HY}$, Ko BS, Yao M, et al. Isolation of multipotent cells from human term placenta. Stem Cells 2005;23:3-9.

48. Anker PS, Scherjon SA, Klijburg-van der Keur C, Noort WA, Claas FH Willemze R, et al. Ammiotic fluid as a novel source of mesenchymal stem cells for therapeutic transplantation. Blood 2003;102:1548-9.

49. Halvorsen YC, Wilkison WO, Gimble JM. Adipose-derived stromal cells-their utility and potential in bone formation. Int J Obes Relat Metab Disord 2000;24 Suppl 4:S41-S44.

50. Zuk PA, Zhu M, Mizuno H, Huang J, Futrell JW, Katz AJ, et al. Multilineage cells from human adipose tissue: implications for cell-based therapies. Tissue Eng 2001;7:211-28.

51. Dominici M, Le Blanc K, Mueller I, Staper Cortenbach I, Marini F, Krause $D$ et al. Minimal criteria for defining multipotent mesenchymal stromal cells. The International Society for Cellular Therapy position statement. Cytotherapy 2006;8:315-7.

52. Engela AU, Baan CC, Dor FJ, Weimar W, Hoogduijn MJ. On the interactions between mesenchymal stem cells and regulatory $\mathrm{T}$ cells for immunomodulation in transplantation. Front Immunol 2012;3:126. doi: 10.3389 / fimmu.2012.00126

53. Seifert, M., Stolk, M., Polenz, D., and Volk, H. D. Detrimental effects of rat mesenchymal stromal cell pre-treatment in a model of acute kidney rejection. Front. Immunol.2012; 3:202. doi: 10.3389/fimmu.2012.00202

54. Leijs, M. J., Van Buul, G. M., Lubberts, E. Bos, P. K., Verhaar, J. A., Hoogduijn, M. J., et al. Effect of arthritic synovial fluids on the expression of immunomodulatory factors by mesenchymal stem cells: an explorative in vitro study. Front Immunol 2012;3:231.
55. De la Rosa O, Dalemans W, Lombardo E. Toll-like receptors as modulators of mesenchymal stem cells. Front Immunol 2012:3:182. doi: 10.3389/ fimmu.2012.00182

56. Ebert AD, Diecke S, Chen YI, Wu JC. Reprogramming and transdifferentiation for cardiovascular development and regenerative medicine: where do we stand?. EMBO Mol Med 2015;1-14 DOI 10.15252/emmm.201504395

57. Leri A, Kajstura J, Anversa P. Role of cardiac stem cells in cardiac pathophysiology: a paradigm shift in human myocardial biology. Circ Res 2011;109:941-61

58. Sanganalmath SK, Bolli R. Cell therapy for heart failure: a comprehensive overview of experimental and clinical studies, current challenges, and future directions. Circ Res 2013;113:810-34

59. Silva GV, Litovsky S, Assad JA, Sousa AL, Martin BJ, Vela D, et al. Mesenchymal stem cells differentiate into an endothelial phenotype, enhance vascular density, and improve heart function in a canine chronic ischemia model. Circulation 2005;111:150-6.

60. Miyahara Y, Nagaya N, Kataoka M, Yanagawa B, Tanaka K, Hao $\mathrm{H}$, et al. Monolayered mesenchymal stem cells repair scarred myocardium after myocardial infarction. Nat Med 2006;12:459-65.

61. Hare JM, Fishman JE, Gerstenblith G, DiFede Velazquez DL, Zambrano JP, Suncion VY, et al. Comparison of allogeneic vs autologous bone marrowderived mesenchymal stem cells delivered by transendocardial injection in patients with ischemic cardiomyopathy: the poseidon randomized trial. JAMA 2012;308:2369-79.

62. Habeeb MA, Vishwakarma SK, Bardia A, Khan AA. Hepatic stem cells: A viable approach for the treatment of liver cirrhosis. World J Stem Cells 2015;7:859-65

63. Shi X, Lv S, He X, Liu X, Sun M, Li M, et al. Differentiation of hepatocytes from induced pluripotent stem cells derived from human hair follicle mesenchymal stem cells. Cell Tissue Res 2016;Apr 7. [Epub ahead of print]

64. Wang Y, Yu X, Chen E, Li L. Liverderived human mesenchymal stem cells: a novel therapeutic source for liver diseases. Stem Cell Res Ther 2016;12;7:71. doi: 10.1186/s13287-016-0330-3. 
65. Chen JS, Wong VW, Gurtner GC. Therapeutic potential of bone marrowderived mesenchymal stem cells for cutaneous wound healing. Front Immunol 2012;3:192. doi: 10.3389/ fimmu.2012.00192

66. Wong VW, Sorkin M, Glotzbach JP, Longaker MT, Gurtner GC. Surgical approaches to create murine models of human wound healing. J Biomed Biotechnol 2011, 969618 doi: 10.1155/2011/969618. Epub 2010 Dec 1. Review.

67. Ribeiro J, Pereira T, Amorim I, Caseiro AR, Lopes MA, Lima J, et al. Cell Therapy with Human MSC Isolated from the Umbilical Cord Wharton Jelly Associated to a PVA Membrane in the Treatment of Chronic Skin Wounds. Int J Med Sci 2014;11:979-87

68. Badiavas EV, Falanga V. Treatment of chronic wounds with bone marrowderived cells. Arch. Dermatol 2003;139:510-516.

69. Freitag J, Dan Bates D, Boyd R, Shah $\mathrm{K}$, Barnard A, Huguenin L, Tenen A. Mesenchymal stem cell therapy in the treatment of osteoarthritis: reparative pathways, safety and efficacy - a review. BMC Musculoskeletal Dis 2016;17:230. DOI 10.1186/s12891-016-1085-9

70. Centeno CJ, Busse D, Kisiday J, Keohan C, Freeman M, Karli D. Increased knee cartilage volume in degenerative joint disease using percutaneously implanted, autologous mesenchymal stem cells. Pain Physician 2008;11:343-53.

71. Jo CH, Lee YG, Shin WH, Kim H, Chai JW, Jeong EC, et al. Intra-articular injection of mesenchymal stem cells for the treatment of osteoarthritis of the knee: a proof-of-concept clinical trial. Stem Cells 2014;32:1254-66.

72. Centeno C, Schultz J, Cheever M. Safety and complications reporting on the re-implantation of culture-expanded mesenchymal stem cells using autologous platelet lysate technique. Curr Stem Cell 2011;5:81-93.

73. Peng L, Jia Z, Yin $X$, Zhang $X$, Liu $\mathrm{Y}$, Chen $\mathrm{P}$, et al. Comparative analysis of mesenchymal stem cells from bone marrow, cartilage, and adipose tissue. Stem Cells Dev 2008;17:761-74.

74. Alvarez-Viejo M, Menendez-Menendez Y, Blanco-Gelaz MA, Ferrero-Gutierrez
A, Fernandez-Rodriguez MA, Gala J, et al. Quantifying mesenchymal stem cells in the mononuclear cell fraction of bone marrow samples obtained for cell therapy. Trans Proc 2013;45:434-9

75. Kern S, Eichler H, Stoeve J, Klüter $\mathrm{H}$, Bieback K. Comparative analysis of mesenchymal stem cells from bone marrow, umbilical cord blood, or adipose tissue. Stem Cells 2006;24:1294-301.

76. Pers YM, Rackwitz L, Ferreira R, Pullig O, Delfour C, Barry F, et al. ADIPOA Consortium. Adipose Mesenchymal Stromal Cell-Based Therapy for Severe Osteoarthritis of the Knee: A Phase I Dose-Escalation Trial. Stem Cells Transl Med 2016 May 23. pii: sctm.2015-0245. [Epub ahead of print].

Correspondencia: José Luis Aguilar Olano Dirección: Av. Honorio Delgado 430 SMP Lima

Teléfono: 992751437

Correo electrónico:jose.aguilar@upch.pe

\section{Suscríbete a nuestro canal de Youtuhe y disfruta la mejor y más completa información de investigación científica}

wWw.youtube.com/RPMESP

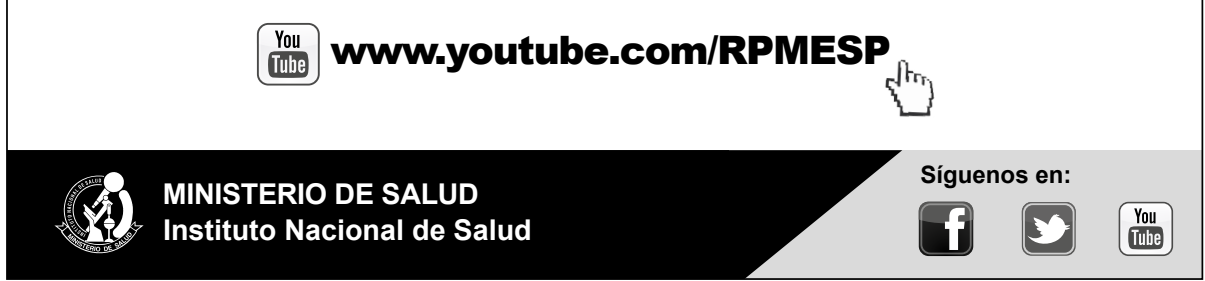

